\title{
EL PROYECTO DE JUAN JIMÉNEZ DONOSO PARA LA CONSTRUCCIÓN DEL PALACIO VIRREINAL DE BOGOTÁ*
}

\author{
GUADALUPE ROMERO-SÁNCHEZ ${ }^{1}$ \\ IVÁN PANDURo SÁEZ ${ }^{2}$ \\ Universidad de Granada
}

\begin{abstract}
La ciudad de Santafé en el Nuevo Reino de Granada nunca contó con una sede digna para la representación del poder real. Esta carencia se hizo aún más evidente después de su designación como capital de un nuevo virreinato y de la elección del inmueble que se convertiría en palacio de los virreyes. Construido de tapias y con pisos muy bajos, la apariencia de este edificio era modesta y amenazaba ruina, por ello, se ordenó la ejecución en diferentes momentos de diversos proyectos para su reconstrucción. Uno de ellos será el realizado por el ingeniero Jiménez Donoso, proyecto muy desconocido que encierra numerosos datos inéditos sobre el edificio antiguo y la nueva obra, datos que consideramos de enorme interés para la historia constructiva de Bogotá.
\end{abstract}

Palabras clave: Palacio Virreinal; Siglo XVIII; Virreinato del Nuevo Reino de Granada; Juan Jiménez Donoso; Santafé.

\section{THE PROJECT OF JUAN JIMÉNEZ DONOSO FOR THE RECONSTRUCTION OF THE VICEROY'S PALACE OF BOGOTA}

The city of Santafé of the New Kingdom of Granada has never had headquarters worth of representing the royal power. This shortage became even more evident after its designation as the capital of the Viceroyalty of New Granada and the selection of a building that would be turned into the Viceroy's Palace. Constructed of blocks and with very low floors, the appearance of this building was modest and falling into ruins. For that reason, several reconstruction projects were ordered in different times. One of them was realized by the engineer Jiménez Donoso, a little-known project containing unpublished facts about the building and the reconstruction, information that we consider of great interest for the architectural history of Bogotá.

Key words: Viceroy`s Palace; 18th Century; Viceroyalty of New Kingdom of Granada; Juan Jiménez Donoso; Santafé.

Cómo citar este artículo / Citation: Romero-Sánchez, Guadalupe/Panduro Sáez, Iván (2020): "El proyecto de Juan Jiménez Donoso para la construcción del palacio virreinal de Bogotá". En: Archivo Español de Arte, vol. 93, núm. 371, Madrid, pp. 259-276. https://doi.org/10.3989/ aearte.2020.17.

\section{Breve historia del palacio virreinal de Bogotá hasta el terremoto de 1785}

Desde que se estableciera la capital del virreinato de Nueva Granada en Santafé en 1717 y fuera reinstaurada en 1739, los virreyes neogranadinos habitaron un palacio, heredado en parte

* Investigación desarrollada en el marco del Proyecto de Investigación "Relaciones artísticas entre Andalucía y América. Los territorios Periféricos: Estados Unidos y Brasil” (HAR2017-83545-P), MINECO, del que formamos parte. Agradecemos a Rafael López Guzmán, su IP, su generosidad en esta investigación.

1 guadalupers@ugr.es / ORCID iD: https://orcid.org/0000-0003-3865-3579

2 ivanps@ugr.es / ORCID iD: https://orcid.org/0000-0002-8979-5991 
del siglo XVI, que se encontraba en completa ruina, hecho que motivó que prácticamente todos los dignatarios solicitaran su reedificación o su reforma casi completa.

El origen del edificio y su devenir en los siglos subsiguientes es bastante desconocido y cuenta con lagunas documentales importantes, no obstante, vamos a intentar desarrollar un hilo temporal coherente con los datos existentes. Si atendemos a la documentación histórica el edificio sobre el que se asentó el palacio virreinal en el siglo XVIII había sido construido muy poco tiempo después de fundarse la ciudad en $1539^{3}$. En los primeros tiempos en Santafé no hubo Casas Reales, es decir, no existía una sede fija para los mandatarios representantes directos de la Corona $^{4}$, aunque con el tiempo esta carencia se suplió gracias a los esfuerzos de la Real Audiencia quien adquiriría una vivienda de dos plantas, situada en la esquina oriental del costado sur de la Plaza Mayor, que había servido tiempo atrás como residencia del conquistador Hernán Venegas 5.

En un principio tanto el espacio destinado a Audiencia como la residencia real tuvieron que ser alquiladas, pues no se había decidido de manera definitiva la ciudad asignada como sede en el Nuevo Reino de Granada ${ }^{6}$, no obstante, hacia 1561, los oficiales de la Real Hacienda ya informaban al rey de que "Vuestra Magestad tiene compradas en esta çiudad de Santafé dos casas principales: la una costó cuatro mil ochoçientos pesos de buen oro, que es donde al presente está la Real Audiencia y suelen vivir algunos oidores" ${ }^{\prime 7}$. A partir de este momento, y como señala Rodríguez Freyle, a este edificio se le conocería desde el último cuarto del siglo XVI con el nombre de palacio o de Casas Reales, título que también compartiría con la sede de la Real Audiencia ${ }^{8}$.

Del edificio del siglo XVI apenas se conservarían restos en el momento de su conversión a palacio virreinal pues el edificio sufrió numerosas reparaciones e intervenciones con el paso del tiempo, siendo la primera obra documentada en 1583 estando a cargo la tasación por el maestro albañil Antonio Díaz, una de las personas que intervinieron en la colocación de la primera piedra de la catedral o iglesia mayor el 12 de marzo de $1572^{9}$.

La que sería la sede del palacio virreinal, objeto de nuestro estudio, se fijó sobre este edificio del costado sur de la Plaza Mayor, ocupando toda la manzana comprendida hoy entre las carreras $7^{\mathrm{a}}$ y $8^{\mathrm{a}}$ y las calles 9 y 10. Lo conformaban todo un "conglomerado de construcciones de distintas épocas, comprendía, además de la vivienda del virrey, las oficinas de la Audiencia, las Cajas Reales, la fundición de la Moneda, el Cuartel de Infantería, los almacenes de bulas y papel sellado y los que servían para guardar especies (mantas, lienzos de algodón, alpargatas, etc.) en que los indios pagaban sus tributos"10.

Inevitablemente tenemos que dar un salto en el tiempo y aventurarnos hasta el siglo XVIII donde volvemos a tener noticias sobre el palacio. No obstante, antes de referenciar estos acontecimientos es importante que nos detengamos, aunque sea brevemente, en exponer algunos datos

3 Testimonio de Messía de la Cerda, 1 de febrero de 1761, Archivo General de Indias (AGI), Santa Fe, 577 A.

4 Martínez, 1987: 284.

${ }^{5}$ Al igual que las Casas Reales de Santafé, en los casos de Nueva España y del Perú el palacio virreinal tuvo su origen en las casas de los conquistadores. En México la cuadra de la Plaza Mayor que comprendía las conocidas como Casas de Cortés, — asentadas sobre el palacio de Moctezuma_, perteneció a la familia del conquistador hasta 1563 cuando la Corona compra dicho solar a su hijo Martín Cortés, el II marqués del Valle de Oaxaca. Castro, 2003.

Similar cuestión se dio en Perú cuando las Casas del Marqués Pizarro - construidas sobre una huaca prehispánica y algunas de las dependencias del curaca Taulichusco - pasaron a la nómina de la administración en 1557, por entonces en propiedad de su hija Francisca Pizarro, como cobro de unas deudas que el conquistador había contraído en vida. Martín, 1938.

Además, en los tres casos y en el posterior nacimiento del virreinato de la Plata en 1776 — si bien en México y Lima con mayor intensidad por la pronta capitalidad de los virreinatos - las Casas Reales supusieron desde el punto de vista urbanístico un centro geográfico del poder, no solo porque se establecieron en las plazas mayores junto a los poderes religiosos y el cabildo, sino que también la nobleza que llegaba a América pretendía edificar sus palacios a la estela del status social que de estos se irradiaba.

6 Mejía, 2012: 207. Friede, 1955: 20.

7 Friede, 1975-1976: 197.

8 Rodríguez, 1979: 235.

9 Flórez, 1990: 131.

${ }_{10}$ Marco, 1949: 89. 


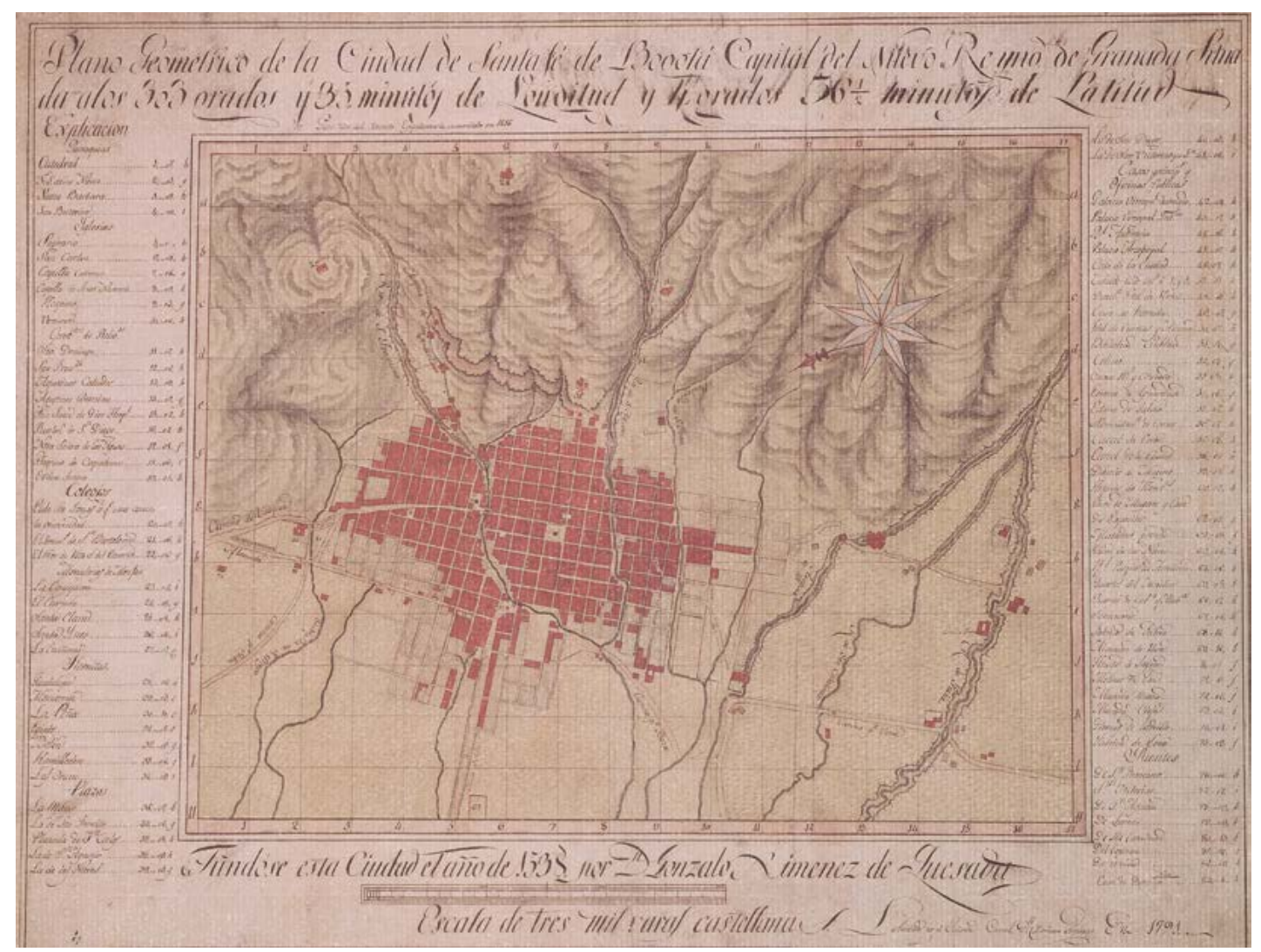

Fig. 1. Plano geométrico de la ciudad de Santafé de Bogotá de Domingo Esquiaqui, IGN, 12-L-25 (51-MAPA01). CC-BY 4.0 scne.es 2010.

sociales o espaciales de Santafé a manera contexto histórico. Con la instauración definitiva del virreinato se produce en Bogotá un nuevo impulso renovador que López diferencia en dos momentos, por un lado la etapa de instalaciones, que dura unos diez años y que traería consigo medidas de control como la realización de censos y la división política de la ciudad, y por otro, a partir de 1781, cuando se produce una fase de ofensiva en la aplicación de los controles y de la fiscalidad ${ }^{11}$.

Es a partir de 1770 cuando las reformas urbanas y las mejoras del ornato público comienzan a materializarse en la ciudad de Santafé, así se dictan normas para el empedrado de las calles, algunas de las cuales se transforman en paseos, planificándose además la construcción de alamedas que tendrán una gran significación social. Por otro lado, los censos de población realizados en la ciudad nos ofrecen datos que oscilan entre 20.000 y 30.000 personas en estas fechas, lo que hace de Santafé una ciudad modesta, como puede observarse en el plano de Esquiaqui ${ }^{12}$ [fig. 1].

Volviendo al tema que nos ocupa, debemos decir que en lo relativo al palacio su situación en tiempos virreinales no cambiará demasiado a pesar de los esfuerzos de los virreyes por mejorar su imagen y devolverle su "dignidad". De mediados de siglo existen algunos informes donde se comunicaba al rey la situación ruinosa del edificio y lo poco apropiado que resultaba su uso. El más antiguo es el emitido por Messía de la Cerda en 1761, el mismo año de su toma de posesión como virrey ${ }^{13}$. En él se informaba de que el palacio era muy "reducido" y su fábrica "antiquísi-

\footnotetext{
11 López, 2006: 122.

12 Pérez, 1883.

13 Testimonio de Messía de la Cerda, 1 de febrero de 1761, AGI, Santa Fe, 577 A.
} 
ma", motivo por el cual tenían que estar reparándolo constantemente, habiéndose gastado hasta el momento una elevada suma de dinero en este concepto. Por otro lado, al tener incorporada a la vivienda los almacenes con los productos derivados de los tributos de los indios (muchos de los cuales se echaban a perder por la humedad de los cuartos bajos) y las salas de fundición de metales manifestaba evidente riesgo de incendiarse frecuentemente "por su mala construcción, antigüedad de fábrica y ser sumamente baja de techos", así, teniendo en cuenta que otras viviendas colindantes, como el cuartel de infantería, tenían los mismos defectos, planteaba reparar los inmuebles para evitar su ruina, presupuestando el coste de las obras entre 12.000 y 16.000 pesos y proponiendo la sufragación de su costo del ramo de penas de cámaras.

El 17 de febrero de 1764, después de haber gastado más de 4.000 pesos en las obras de reparación, comprendió que lo más oportuno era levantar un edificio de nueva planta y así lo comunicó a la Corte, proponiendo que su importe podría atenderse con el producto de la venta del tabaco ${ }^{14}$. En octubre de ese mismo año insistirá en sus argumentaciones añadiendo "...que por la indecencia con que viven los virreyes sonrojados de conocer que cualquiera particular logra en su propia casa hospedage más cómodo, seguro y extenso..." 15 .

En 1765 el Consejo de Indias manifestó la necesidad de que se enviasen planos de la obra que se pretendía realizar antes de tomar una decisión al respecto, hecho que pareciera nunca se produjo $^{16}$, no obstante, hemos podido averiguar lo contrario. En una carta remitida en 1776 por el virrey Flórez se precisaba que debía realizarse "un diseño arreglado, y menos costoso que el que remitió mi antecesor" ${ }^{17}$, quedando en evidencia la existencia de un proyecto anterior. Es cierto que Manuel Guirior fue virrey de Nueva Granada entre 1772 y 1776, tras Messía de la Cerda y fue su sucesor Flórez Maldonado, por lo que, pudiera entenderse que los planos realizados se realizaron durante el mandato de Guirior, no obstante, en dicha carta se especifica que ese diseño lo propuso y remitió su "antecesor el marqués de la Vega"18, es decir, Messía de la Cerda ${ }^{19}$.

De esa carta se extraen además otros datos. En el informe se exponían argumentaciones de lo infructuosos e inútiles que eran los gastos que solían realizarse en el edificio para adecentarlo con motivo de la llegada de un nuevo virrey; se razonaba sobre el mal estado del edificio, que era muy antiguo y estaba tan deteriorado que no admitía reparo, aún así se había invertido ya alrededor de 16.000 pesos en él, y a pesar de ello, el inmueble seguía siendo tan incómodo e imperfecto como al principio. Por ello, y según su opinión, convenía informar al rey de ello porque "sirviendo de habitación a los virreyes y deviendo tenerla con la decencia correspondiente a su alto carácter, combenía rehedificarlo de nuevo, librando Su Magestad las cantidades que fuese necesarias, declarando que los subscritos virreyes la amueblasen y adornases de su quenta, como adaptare a su genio y gusto" 20 . Más adelante añade la necesidad de construirlo desde los cimientos por la amenaza de ruina de varias de sus dependencias entre las que se contaba las habitaciones destinadas a cajas reales, almacenes de efectos de tributos, cuartel de la tropa y de su guardia y fundición de oros ${ }^{21}$.

En la respuesta dada por el Consejo a la carta de Flórez en 1777 se solicita que en lo relativo al palacio el virrey encargara un diseño para la nueva planta del edificio y lo remitiera junto a su presupuesto, informando además del ramo o arbitrio que se destinaría para su construcción ${ }^{22}$. A esta orden contestará el virrey exponiendo que no había en Santafé ninguna persona con conocimientos suficientes para ejecutarlo y que la única solución era requerir al ingeniero militar An-

14 Marco, 1949: 89.

15 Carta de Messía de la Cerda, octubre de 1761, AGI, Santa Fe, 577 A.

16 Gutiérrez / Vallín / Perfetti, 1999: 68.

17 Carta de Flórez, 30 de agosto de 1776, AGI. Santa Fe, 577 A.

18 Construcción de palacios de virreyes, 1 de octubre de 1777, AGI, Indiferente, 1515, sp.

19 El Marquesado de la Vega de Armijo databa de 1679, momento en el que el rey Carlos II lo concede a Fernando Antonio Messía de la Cerda y Angulo, VII Señor de la Vega de Armijo. Este título lo heredaría el virrey Messía de la Cerda por vía paterna.

${ }^{20}$ Construcción de palacios de virreyes, 1 de octubre de 1777, AGI, Indiferente, 1515, sp.

21 Construcción de palacios de virreyes, 1 de octubre de 1777, AGI, Indiferente, 1515, sp.

${ }^{22}$ Construcción de palacios de virreyes, 1 de octubre de 1777, AGI, Indiferente, 1515, sp. Nota 1 
tonio de Arévalo, quien se hallaba en Cartagena de Indias ejerciendo como ingeniero jefe de esa Comandancia, para que enviara un artífice que pudiera cumplir con el encargo ${ }^{23}$. Acompaña al testimonio una descripción con nuevas argumentaciones sobre la necesidad de su construcción:

cualquiera particular de los prinçipales de esta çiudad vivía más acomodado que el virrey, con otras reflexiones y noticias a que me remito por ser çiertas y justas, a las quales añado una particular, y es que las Salas de Juntas, así antigua como moderna, la pieza de mi despacho en donde estoy lo más del día y toda la prima noche hasta las 9 della, y la secretaría no tienen más luz que la que les viene por las ventanas que caen al patio de la cárzel, de esto resulta que yo y los demás que tenemos precisión de estar en dichas piezas leyendo, escribiendo o conferenciando, estamos oyendo continuamente, sin poder evitarlo, el ruido de los grillos, cadenas, gemidos de los que castigan y conversaçiones de los presos, incomodidad que creo no la tiene el más infeliz alcalde de aldea ${ }^{24}$.

El virrey recibiría la autorización requerida pues Arévalo le encargó la comisión al ingeniero Juan Jiménez Donoso (o Ximénez Donoso), quien cumpliría con la comisión. La visita de Donoso a Santafé se ejecutó entre 1779 y 1780, pues en enero de 1781 solicitó las gratificaciones correspondientes "no del proyecto de palacio, cárcel y cuarteles de la capital, porque ya en Santafé se le dio dinero, sino por otros en los que había estado comisionado" desde que seis años antes llegara a la ciudad de Cartagena ${ }^{25}$.

Los planos realizados por este ingeniero no sólo concernían al palacio sino también a otros edificios circundantes, así los planos relacionados con los reparos de la Real Audiencia fueron recibidos en Santafé el 1 de marzo de 1781, junto al presupuesto de la obra. Por otro lado, las planimetrías de la manzana del palacio se firmaron en Cartagena en agosto de ese mismo año, desconociéndose el alcance de su aceptación pues su proyecto quedaría sin ejecución al declararse 5 años más tarde un incendio que destruiría gran parte del viejo edificio, ya ampliamente afectado por un terremoto ocurrido el año anterior.

Por razones cronológicas, puesto que son posteriores a nuestro marco temporal, no vamos a detenemos en analizar pormenorizadamente las consecuencias de estos desastres, no obstante, es interesante exponer que la intensidad del incendio fue tan alta que duró 12 días, tras los cuales no hubo más remedio que demolerlo, dando el rey la orden de reedificarlo según los planos ejecutados que fueron remitidos a la Corte ${ }^{26}$.

Esta orden no tuvo efecto pues en 1787, en el informe que emitiera Domingo Esquiaqui a instancias del virrey Ezpeleta, se solicitaba de nuevo la confección de planos. De este documento se extrae información interesante, cerrando aquí la historia del edificio en lo concerniente a la época de Jiménez Donoso. En este informe se especifica lo siguiente:

El Palacio del Virreynato en esta capital era obra antigua, de mala construcción y sin las distribuciones necesarias para su mejor uso, los materiales de sus principales paredes maestras y colaterales de tierra apisonada en su maior parte o las formadas de las que llaman tapias y de ladrillo crudo o adobes, desunidos en su travazón para su mejor firmeza (construcción común como siguen todos los edificios de esta capital). Los texados, que cubrían estas obras, de armaduras déviles, de poca unión y travazón //254r resíproca, y como era el edificio antiguo, sus maderas malas y carcomidas y de poca recistencia, por cuyas circunstancias previniéndose el eminente riesgo de una ruina, anteriormente, los años pasados, le apuntalaron en su corrido primer suelo, comprehendiendo en este la real contaduría y tesorería de estas reales caxas, como asímismo se entendió esta precaución por lo que se beía en todo lo vajo del tribunal de cuentas. Por las resultas que se manifestaron en el temblor de mil setecientos ochenta y cinco fue preciso de nuevo recorrer lo sostenido en los mencionados puntales anteriores y renovar con otros, cadenando los suelos inferiores con pies derechos hasta llegar a las armaduras de los texados.

\footnotetext{
23 Marco, 1949: 90.

24 Instancia, 31 de marzo de 1778, AGI. Santa Fe, 577-A.

25 Solicitud de gratificaciones, 19 de enero de 1781, AGI, Santa Fe, 593, 1356.

26 Ojeda / Castellanos / Torres, 2013: 177.
} 
En la fábrica de la Real Audiencia sigue el mismo sisthema de construcción que en la del palacio y tribunal de cuentas, y solo hay de firme la esquina derecha, que es obra posterior de sillares ${ }^{27}$.

\section{Juan Jiménez Donoso. Apuntes para una biografía}

La vida del ingeniero Donoso es aún bastante desconocida a pesar de su presumible intensa actividad desarrollada en América, en África y en España, contando en 1785 con 30 años de servicio. Los escasos datos biográficos que conocemos nos lo proporciona de puño y letra el propio Donoso, quien en una obra que publicó a fines del XVIII incorpora una breve reseña autobiográfica ${ }^{28}$.

Comenzó la carrera de armas de cadete en el Regimiento de Infantería de Zamora y estudió matemáticas en la Real y Militar Academia de Barcelona, donde alcanzó el grado de alférez. Con el tiempo se especializó en los rudimentos de las estructuras defensivas, definiendo su actividad así

mi profesión es la colocación de fortalezas, su clase, tamaño, figura, defensa en particular de ellas, y en general de los Estados; como su construcción, guarnición, provisiones de guerra y boca, junto con su entretenimiento, ataque y defensa, con arreglo á los fondos de cada provincia y en general del Erario de la Monarquía $[\ldots]^{29}$.

Según se desprende de Marco Dorta, trabajó en las obras del muelle y fortificaciones de Málaga, en el alcázar de Orán, en la Fábrica de Tabacos de Sevilla, en las plazas fuertes de Extremadura y en la reparación de las murallas de Cádiz. Destinado a la Habana, trabajó en las obras del fuerte de la Cabaña y "construyó el fuerte provisional del Príncipe" 30.

La fecha en la que partió hacia América la desconocemos, aunque en la década de los 60 del siglo XVIII ya debía encontrarse en el continente. Este hecho lo atestigua un discurso que pronunció en La Habana el 30 de abril de 1770 con motivo del acto de apertura del curso de Matemáticas, celebrado en la Real Universidad del Máximo doctor San Jerómino, en calidad de "cathedrático propietario de prima", teniente del cuerpo de ingenieros ${ }^{31}$.

El 30 de junio de 1775, siendo capitán de ingenieros y hallándose en Cartagena de Indias a las órdenes de Arévalo, solicita el ascenso al grado de teniente coronel e ingeniero de $2^{\mathrm{a}}$, petición que es vista favorablemente por el gobernador de la ciudad Juan Pimienta. Unos meses más tarde el general Abarca se manifiesta de manera contraria al referir que hacía poco tiempo se le había ascendido a ingeniero ordinario y que no tenía méritos nuevos para justificar esta nueva propuesta, en consecuencia se le deniega ${ }^{32}$.

Probablemente fuese en 1775 cuando llegara a Cartagena de Indias pues en una solicitud de gratificaciones dada en el 81 expone que hacía 6 años que servía en esa plaza. En esos años participó en diferentes comisiones, entre ellas el testado de la obra que había de "serrar a Bocagrande media legua empleándose indiferentemente en esta y sus planos como en los cortes de maderas y a canteras aún más distantes, reconocimiento del dique de unas treinta leguas que de esta ciudad ay al puerto de Barranca en el río de la Magdalena, para formar el proyecto de hacerlo navegable en todo tiempo" 33 . También ejecutó la reparación de los castillos de la Boca del Pueres o la construcción de cuarteles provisionales como los de Turbaco.

27 Informe de Esquiaqui, 23 de junio de 1787, Archivo General de la Nación de Colombia (AGNC), Colonia, Historia Civil, SC 29, 22, D. 3, 253v-254r.

28 Jiménez, 1794.

29 Jiménez, 1794.

30 Marco, 1949: 93.

31 Discurso de Donoso, 30 de abril de 1770, Archivo Histórico Nacional (AHN), Diversos-Colecciones, 28, N. 41, $1 \mathrm{r}-4 \mathrm{r}$.

32 Capel, 1983: 240.

33 Solicitud de gratificaciones de Jiménez Donoso, 19 de enero de 1781, AGI. Santa Fe, 593, 1356. 
En 1782 realiza el plano de la Loma de las Pulgas y parte del río Atrato con su fuerte. Según Capel ${ }^{34}$ desde 1775 hasta 1787 estuvo trabajando para confeccionar los planos del palacio de los virreyes de Bogotá, no obstante, y como hemos referenciado anteriormente esta fecha, que se toma también como base para la catalogación de los planos en el Archivo General Militar de Madrid, no parece viable pues el encargo, como vimos, no se produce hasta años más tarde ${ }^{35}$.

El 9 de enero de 1785, por resolución dictaminada por el rey, se decide que tanto Donoso como Joseph Rodríguez regresen a España, debido "a los muchos años que se hallan destinados en la Comandancia General de Panamá ${ }^{36}$. Como sustituto se elige al ingeniero Joseph Cleraco quien embarca tiempo después con destino al virreinato, no obstante, fallece tras su llegada por lo que el reemplazo no llega a producirse ${ }^{37}$. En 1788 se envía comunicación al rey solicitando la elección de un nuevo candidato para cubrir su puesto ${ }^{38}$, poco después se elige al ingeniero Luis Rico, destinado en el Reino de Galicia ${ }^{39}$. Poco tiempo después el gobernador de Panamá da cuenta de su llegada ${ }^{40}$ informando además de que Donoso seguía en la ciudad por expreso deseo del señor arzobispo-virrey, de hecho, en una carta escrita por éste así se confirma al exponer que "la detención de don Juan Ximénez Donoso dimana de orden mía, por convenir así al servicio del Rey, en que está empleado el referido oficial" 41 . No obstante, con la orden de regreso a España expedida por el rey, el nuevo virrey Gil y Lemos tomará medidas facilitando su vuelta en carta firmada en el $89^{42}$.

Su marcha se produce el 18 de enero de 1790 en la fragata Pineda con destino a Cádiz. La orden fue ejecutada en tiempos del virrey Espeleta, quien comunica al mes siguiente su salida en cumplimiento de una real orden fechada el 13 de mayo de $1789^{43}$.

En 1794 publica la mencionada obra Despertar, estudio de 5 volúmenes editado en Madrid en la Imprenta Real y escrita en Badajoz, lugar donde presuponemos residía. Se desconoce la fecha de su muerte.

\section{El proyecto de Jiménez Donoso}

En el Archivo Histórico Militar de Madrid ${ }^{44}$ se conserva una serie de planos que conforman dos copias del mismo proyecto constructivo realizado por Jiménez Donoso para la manzana donde se ubicaba el palacio virreinal, además de la Real Audiencia, Cárcel y Cuartel que comunicaba con uno de los frentes de la plaza mayor de la ciudad de Santafé. Están elaborados en papel verjurado, con marcas de agua y montados sobre tela. Diseñados a plumilla con tinta negra y coloreados con acuarela gris, verde y rosa, están manuscritos y cuentan con la firma y rúbrica del autor. A los planos acompañaba una descripción y un presupuesto, hoy desaparecidos, que explicaría con detalle cada elemento reseñado en ellos y que ayudaría sobremanera a su comprensión.

34 Capel (1983:240)

35 En diciembre de 1786 el rey le concede el empleo de ingeniero en segundo de los Reales Ejércitos (1786: 365 ).

${ }^{36}$ Reemplazo de ingenieros, 9 de enero de 1785, Archivo General de Simancas (AGS), Secretaría de Estado y del Despacho de Guerra (SEDG). SGU, LEG 7237,3, 3r.

$37 \mathrm{Al}$ año siguiente se le concede el ascenso a ingeniero en segundo de los Reales Ejércitos, Plazas y Fronteras. Mercurio histórico y político, 1786.

${ }^{38}$ Reemplazo de ingenieros, 1788, AGS, SEDG. SGU, LEG 7237,3 40r.

39 Reemplazo de ingenieros, [1788], AGS, SEDG. SGU, LEG 7237,3 43r.

40 Reemplazo de ingenieros, 8 de octubre de 1788, AGS, SEDG. SGU, LEG 7237,3 52r.

41 Reemplazo de ingenieros, 5 de septiembre de 1788, AGS, SEDG. SGU, LEG 7237,3 53r.

42 Reemplazo de ingenieros, 30 de enero de 1789. AGS, SEDG. SGU, LEG 7237,3 54r.

43 Comunicación del regreso de Donoso, 19 de febrero de 1790, AGI, Santa Fe, 639, 161, duplicado.

44 España. Ministerio de Defensa. Instituto de Historia y Cultura Militar. Archivo General Militar de Madrid (AGMM). Ver: http://www.portalcultura.mde.es/cultural/archivos/. Queremos agradecer especialmente al comandante Agustín Pacheco Fernández, de la sala de investigadores del AGMM, su disposición y colaboración. 

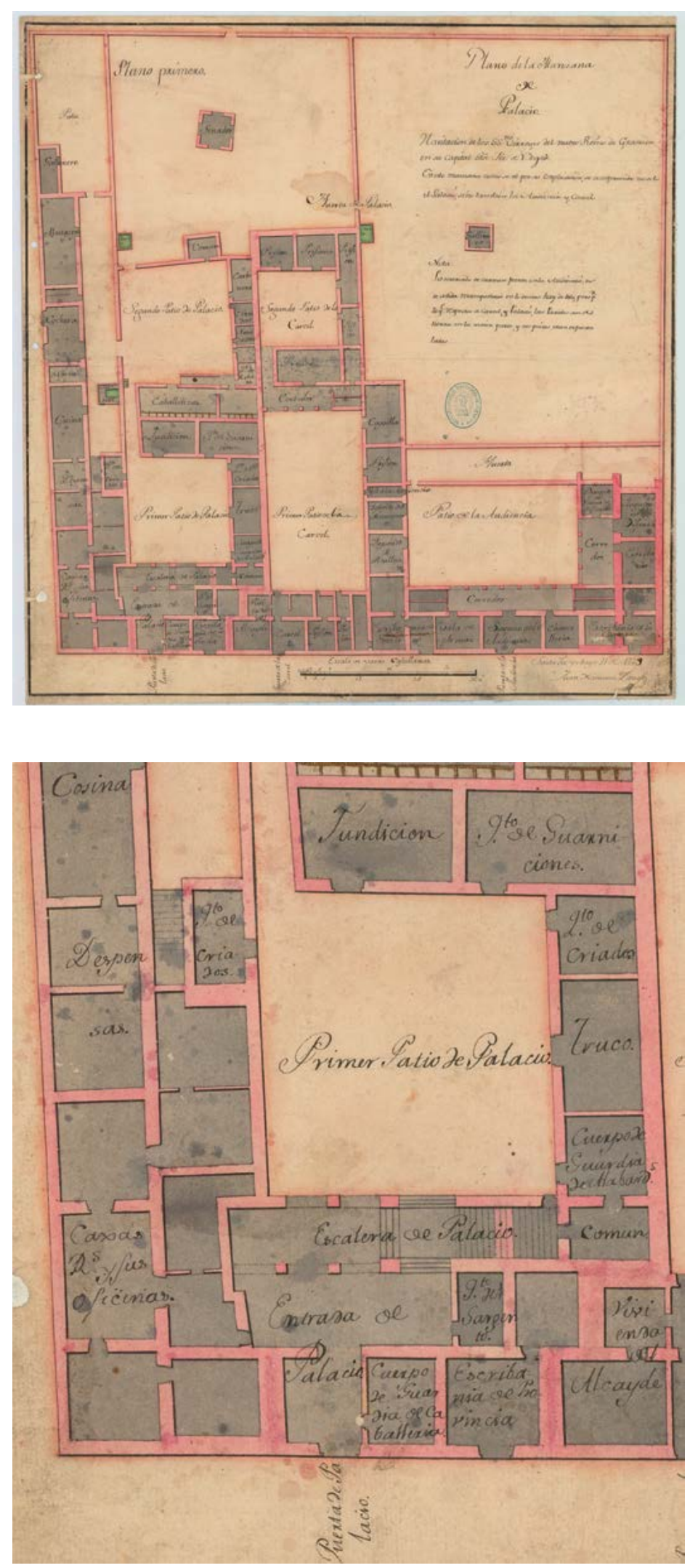

Fig. 2. Plano de la manzana del Palacio de los Virreyes del Nuevo Reino de Granada con la Real Audiencia y Cárcel. AHMM, Sección Cartografías, COL-10-04.
Fig. 3. Plano de la manzana del Palacio de los Virreyes del Nuevo Reino de Granada con la Real Audiencia y Cárcel. Detalle del área del primer patio del palacio. AHMM, Sección Cartografías, COL-10-04. 
Fig. 4. Plano de la manzana del Palacio de los Virreyes del Nuevo Reino de Granada con la Real Audiencia y Cárcel. AHMM, Sección Cartografías,

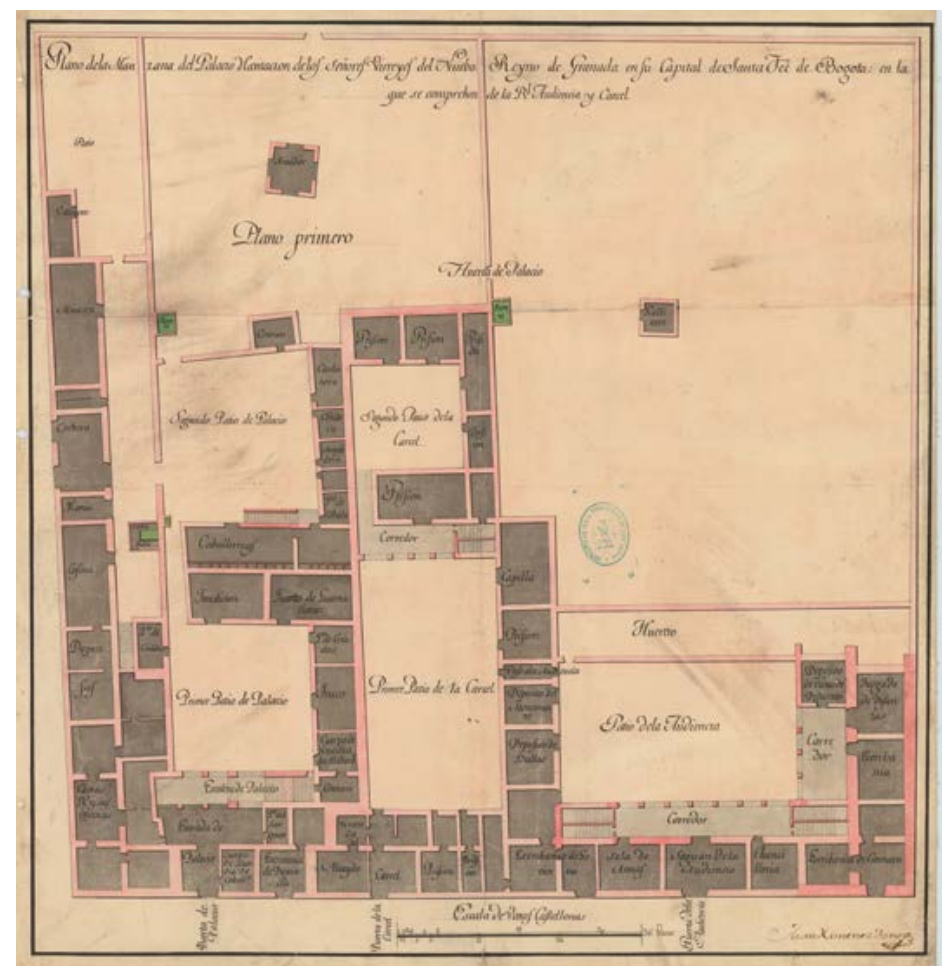

\section{El palacio virreinal de Santafé en tiempos de Donoso}

En estos planos [figs. 2, 3 y 4] se muestra el estado del palacio viejo así como de los edificios adosados a él, cárcel y audiencia, tal y como se encontraban en tiempos de Donoso. Estos pliegos son fundamentales pues ya vimos que sobre el palacio solo hay datos superficiales y no se conservan referencias a su distribución interior, son, por tanto, un testimonio vivo de su disposición, de su estructura, de sus dimensiones y de ahí su inmenso valor.

Las paredes de los planos están coloreadas en tono rosado o carmesí. En el proyecto de Donoso, que se ejecuta sobre la misma manzana, las partes identificadas con este color serán un indicativo de espacios reaprovechados y, por tanto, de muros integrados en la futura obra. Adelantamos que, en lo relativo al palacio, no podrá reaprovecharse nada, recomendándose su absoluta destrucción.

En el encabezado del plano COL-10/04 se advierte asíi5: "Lo marcado de carmesí fuerte en la Audiencia es de sólida mampostería en lo demás hay de todo, pero por lo que respecta a cárcel y palacio las paredes son de tierra en la mayor parte y sus piesas están apuntaladas". Sería la confirmación del mal estado constructivo. Las zonas de la audiencia que presumiblemente estaban levantadas de mampostería eran el perímetro de las escaleras, los pilares del corredor de acceso al patio, la escribanía, la escribanía de cámara, el juzgado de difuntos y el depósito de bienes de difuntos, sin contarse entre ellos los tabiques divisorios, realizados en otro material.

Centrándonos en la descripción del plano, la fachada enfrentada hacia la plaza era la principal. Contaba con tres puertas principales de acceso al palacio, a la cárcel y a la Real Audiencia y con tres secundarias que daban entrada a las tres escribanías (la de Provincia, la de Gobierno y la de

\footnotetext{
45 Plano fechado en Santafé el 21 de mayo de 1779, este dato es importante para certificar la realización de la comisión en esas fechas. El resto de planos datan en su mayoría del 11 de agosto de 1780, estando firmados ya en Cartagena de Indias.
} 
Cámara). El ingreso al palacio estaba custodiado por la guardia de caballería. Tras pasar el zaguán se accedía a un espacio de comunicación protegido por el cuarto del sargento y que daba acceso por su parte izquierda a las cajas reales y sus oficinas. Desde este punto nos dirigimos a través de un pórtico de tres arcos (espacio muy interesante desde el punto de vista arquitectónico) a una habitación (donde se hallaba la escalera principal) que conectaba a través de una doble arcada con el primer patio del palacio. En torno a este patio se localizaba la fundición, la habitación de los criados y los cuartos de guarniciones y de guardia de alabarderos.

Siguiendo por un pasillo muy pronunciado y de forma trapezoidal llegamos al segundo patio del palacio donde se encontraba una escalera secundaria y dependencias en tres de sus lados. Al final de este pasillo había una pila de agua que probablemente funcionada como abrevadero al encontrarse las caballerizas allí. A la derecha aparecen identificadas una serie de habitaciones mencionadas como carbonera, cernidero, amasadero y cuarto de cebada; en su frente solo se advierte una estancia de uso común y una puerta, enfrentada al pasillo, que daba acceso a la huerta (en cuyo entronque se situaba una fuente o alberca). La huerta la conformaba un amplio espacio, delimitado por tapias y dividido en dos partes desiguales que generaban dos usos diferenciados, centrados el primero por un cenador (abierto en sus cuatro frentes y con una orientación ligeramente diferente al del resto de los edificios) y el segundo por un gallinero.

A la izquierda del segundo patio del palacio se accedía a una habitación alargada donde se localizaba el lavadero, dispuesto alrededor de una pila de agua. A la izquierda una escalera secundaria; a la derecha un patio con un segundo gallinero y en el frente el almacén, cochera, horno, cocina y despensas.

La cárcel también se estructuraba alrededor a dos patios. En torno al primero se localizaba la capilla, un paso abierto hacia el patio de la Audiencia, y las salas del depósito del monumento y de bulas. En el frente de la plaza había habitaciones que funcionaban como prisiones, uso que tendrían también todas las dependencias del segundo patio. El acceso a este segundo patio se realizaba a través de un corredor de cuatro arcos donde también se ubicaría la caja de escaleras. En el frente izquierdo no habría ninguna dependencia pues limitaría con la pared del palacio.

Por último la Real Audiencia. El zaguán de entrada daría paso a un corredor porticado hacia el patio, a cuyos lados habría sendos cuerpos de escaleras. En el frente de la plaza se encontraba la sala de armas y la chancillería, además de la escribanía de cámara mencionada con anterioridad. Un segundo corredor porticado en el frente derecho daría acceso a las dependencias de mampostería reseñadas, depósito de bienes de difuntos y juzgado de difuntos. A través de una puerta ubicada en el frente del patio se accedía a un espacio alargado, similar en tamaño al del frente de la plaza, donde estaba el huerto.

\section{Plano Segundo}

En este plano [fig. 5] se representa el palacio de los señores virreyes, "supuesto demolido enteramente el que oy hay por ser sus paredes en la maior parte de tierra y tener sus havitaciones apuntaladas" 46 , se corresponde a la planta inferior y entresuelos. También se representa el piso bajo de la Audiencia y la cárcel. Por último, se incluye el primer cuerpo del cuartel para la compañía de infantería y la de la caballería de la guardia de los virreyes, bajo supuesto de cien hombres cada una, además de las habitaciones para sus oficiales.

La disposición de la manzana varía radicalmente con respecto del edificio heredado, siendo muy ambicioso. En él no solo desaparecen gran parte de las huertas, sino también se modifica el espacio ocupado por los tres edificios de referencia: palacio, cárcel y audiencia. Empezando por el palacio éste ocupará un frente mucho mayor, añadiéndosele gran parte de la antigua cárcel, a excepción del flanco derecho donde se encontraba por ejemplo la capilla. Es así, como la extensión total de este edificio aumentará hasta ocupar prácticamente la mitad de la manzana, amplián-

${ }^{46}$ Copia con signatura COL-10-07. 
Fig. 5. Plano segundo del Palacio de Santafé o primer piso, AHMM, Sección Cartografías, COL-10-09.

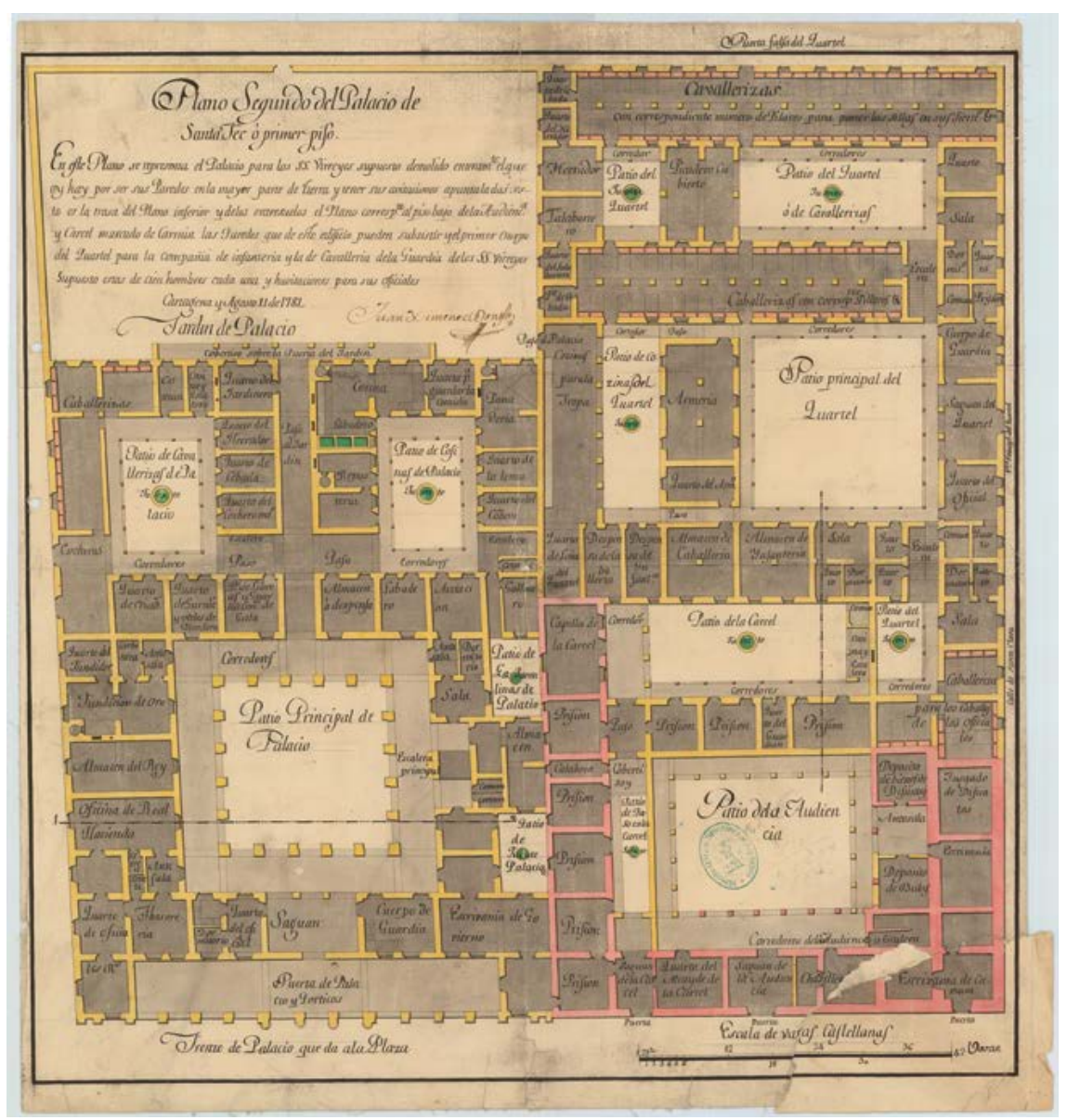

dose el número de habitaciones y también el número de patios que organizan su espacio, siendo los principales del palacio y de la Audiencia los únicos que no contarían con fuentes.

El frente del palacio hacia la plaza lo ocupa un gran pórtico de 13 arcos, de los cuales los tres centrales marcarían el espacio del zaguán al que se accedería desde el arco central. Los dos arcos limítrofes darían acceso a los cuartos de los oficiales reales que comunicaría a su vez con la tesorería, con los retretes y con las salas de la Real Hacienda, con sus correspondientes antesalas; mientras a la derecha se daría acceso a la escribanía de gobierno. El zaguán estaría protegido por el cuerpo de guardia y del oficial y daría acceso a través de una portada de tres arcos al patio principal, porticado en sus cuatro frentes y con sus respectivos corredores. En el centro del lado derecho una escalera monumental que comunicaría con la planta noble del edificio, tras la escalera habitaciones de uso común y almacenes, y a los lados dos pequeños patios con fuentes centrales, denominados el superior de Gallinas, por encontrarse allí el acceso al gallinero, y el inferior de palacio.

En el centro del frente superior un amplio pasillo conectaría con dos salas de paso, formando una "T", que darían acceso a los otros dos patios porticados con los que cuenta el palacio, denominado el de la izquierda "de Caballerizas" y el de la derecha "de Cocinas" con sus respectivas fuentes centrales. Alrededor del primero se localizan las habitaciones homónimas, así como las cocheras, el cuarto del herrador, del cochero mayor, de criados y de cebada. En torno al segundo patio la cocina con su horno, el lavadero y las pilas de agua; la sala de repostería y su horno; la despensa; la panadería y su horno; el cuarto de depósito de carbón y algunas habitaciones más, entre ellas alguna más de lavadero. Entre ambos patios un largo pasillo de acceso al jardín, ubicado en la parte trasera del edificio, con un cobertizo muy alargado proyectado hacia el exterior. Com- 
pleta el conjunto la fundición de oro, que cuenta también con un horno propio, una carbonera y una habitación para el fundidor y el almacén del rey, ubicados a mano izquierda del patio principal.

La cárcel y la Audiencia ocupan algo menos de una cuarta parte de la manzana y se ubican en el costado derecho del frente que da a la plaza. Esta zona es la menos transformada pues, como advertimos, aprovecha gran parte de las edificaciones existentes, aunque, eso sí, cambian de uso. Hacia la plaza se abren 3 puertas, la situada más a la izquierda da acceso al zaguán de la cárcel, la central al zaguán de la Audiencia y la de la derecha a la escribanía de cámara. La prisión se convierte en un edificio alargado, en forma de "L" que ocupa dos frentes del patio principal, denominado de la Audiencia. Ambos frentes tienen una disposición compleja que permite que no se abran puertas ni ventanas al espacio de este patio, guardando la intimidad y facilitando el trabajo de los oficiales reales, que en alguna ocasión se habían quejado del ruido que hacían los presos.

Desde el zaguán de entrada a la cárcel se accede a un patio muy estrecho y alargado que da acceso a la izquierda a una serie de habitaciones dispuestas de forma continua y en su frente a una habitación de paso que comunica con el corredor izquierdo del patio principal de este edificio, ubicado tras pasar el patio de la Audiencia y las habitaciones anejas, que antaño eran un huerto. Ambos patios cuentan con una fuente central. Todas las habitaciones del lado derecho han cambiado de uso a excepción de la capilla que se ubica en el mismo lugar, el que fuera pasillo de comunicación entre la cárcel y la audiencia ahora se ha convertido en el calabozo y el resto de espacio en prisiones, al igual que las dependencias en torno al patio central, porticado en dos de sus frentes, que además alberga la cocina y el cuarto del guardián, entre otros.

La mayor parte de la fachada hacia la plaza está ocupada por el edificio de la Real Audiencia, como es comprensible, en ella, además del zaguán está la Chancillería. El único cambio sustancial que advertimos es la división del corredor de la derecha en dos salas, una convertida en antesala del depósito de bienes de difuntos y otra convertida en el depósito de bulas.

La que había sido la huerta mayor del palacio, donde se encontraba el gallinero, ahora se proyecta como cuartel, ocupando todo su espacio. El edificio es regular, distribuido en torno a cuatro patios de diferente estilo, tamaño y uso. El patio principal es el que se ubica a mano derecha, en la zona inferior, y está porticado en sus cuatro frentes, careciendo también de fuente, como el resto de patios principales de la manzana. El acceso al cuartel se produce por la calle de Santa Clara, estando el zaguán limitado por el cuarto del oficial y el de guardia. El resto de patios son el denominado de cocina, de caballerizas y del cuartel, que nos puede dar una idea de las dependencias anejas.

\section{Plano tercero}

Se refiere a la primera planta o zona noble de los edificios [figs. 6 y 7]. Repite casi exactamente la disposición de las habitaciones inferiores, aunque debemos advertir que la planta alta de la cárcel es ocupada por dependencias de la audiencia y que ésta y el palacio están conectados en altura a través de dos salas.

A la derecha del patio principal se ubica la sala de la virreina y en el extremo contrario la sala del virrey, ambos con su dormitorio, gabinete y retrete, y en el caso de la virreina también con su tocador. Como salas intermedias entre ambos se encontrarían los dormitorios, tocadores y sala de labor de las criadas, así como una cocina habilitada para utilizar en caso de enfermedad, entre otras dependencias. Al otro extremo del patio se ubicaría la escalera monumental con el cuarto del secretario a un lado y la sala del dosel al otro. En el frente principal el salón oficial en el centro, conectado en los extremos con dos amplias salas y abiertos todos hacia la plaza. Alrededor de ellos la antesala de lacayos y de pajes (que servía de paso hacia la Audiencia) y un cuarto habilitado para refresco. El salón de la izquierda comunicaría a su vez con la sala de la virreina.

Alrededor del patio de cocinas se ubicaría la antesala y el comedor, así como la sala donde se depositaría la comida, el cuarto de la plata y la mantelería, el archivo y la secretaría, además de otras habitaciones que entendemos de usos diversos. En torno al patio de caballerizas destacamos la sala del truco, el oratorio con la antesala que da acceso al cuarto del virrey, y el salón 
Fig. 6. Plano tercero del Palacio de Santafé o segundo piso. AHMM, Sección Cartografías, COL-10-05.

Fig. 7. Plano tercero del Palacio de Santafé o segundo piso. AHMM, Sección Cartografías, COL-10-06.
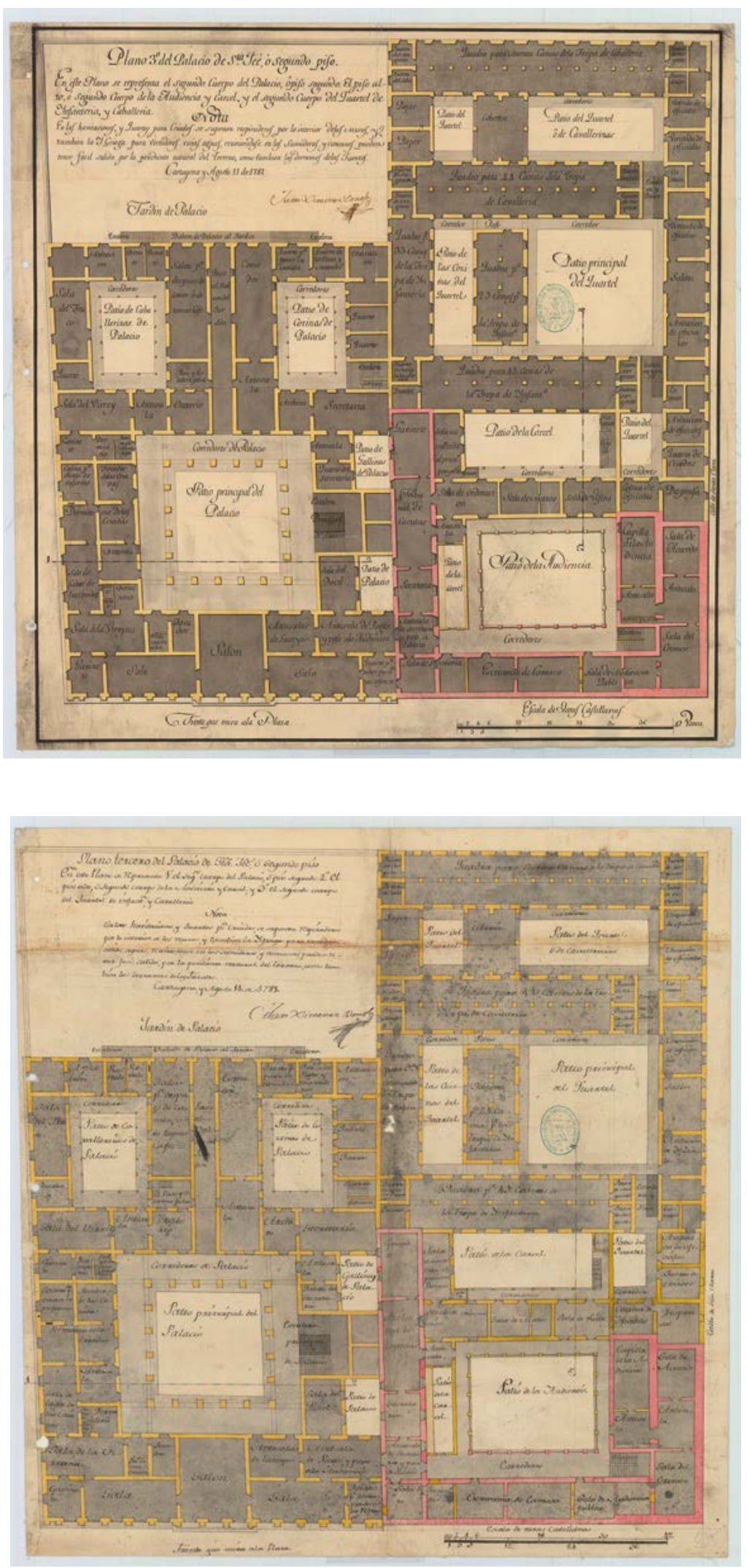

Archivo Español de Arte, vol. XCIII, n. ${ }^{\circ} 371$, pp. 259-276, julio-septiembre 2020 ISSN: 0004-0428, eISSN: 1988-8511, https://doi.org/10.3989/aearte.2020.17 


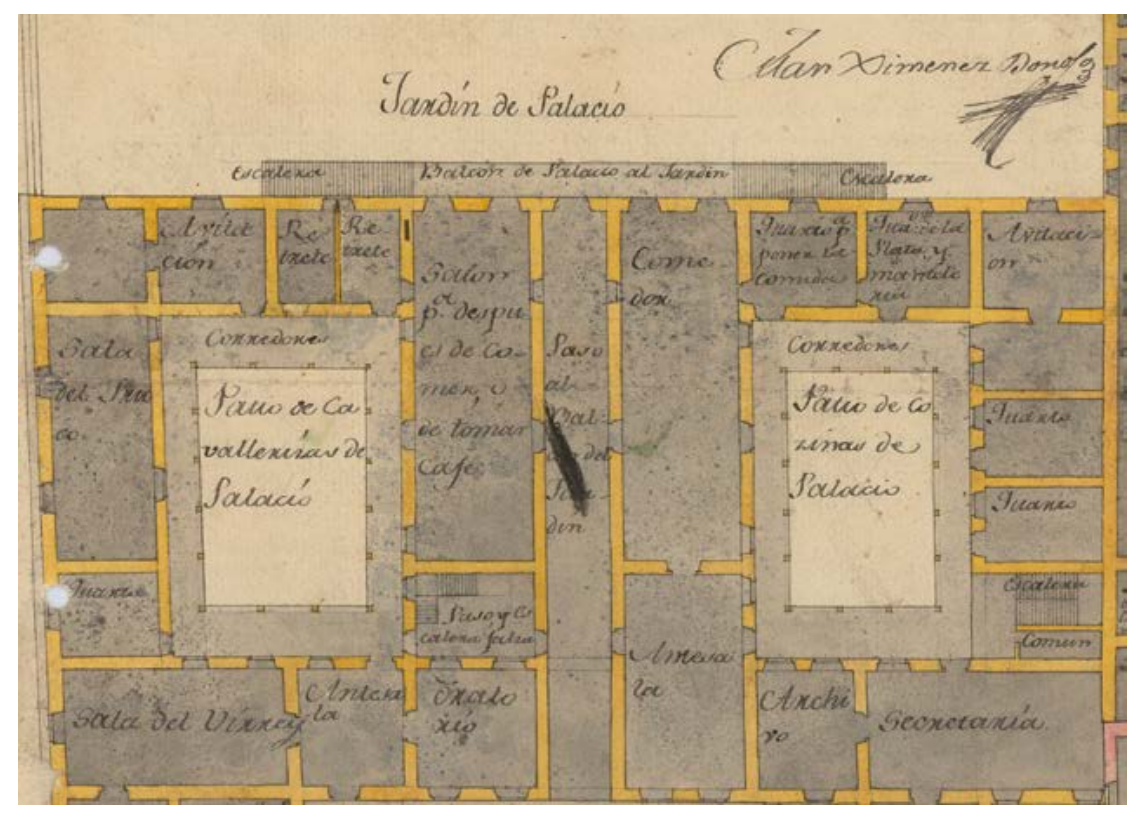

Fig. 8. Plano tercero del Palacio de Santafé o segundo piso. Detalle del acceso al jardín. AHMM, Sección Cartografías, COL-10-06.

"para después de comer o de tomar café", con las mismas dimensiones que el comedor. Entre ambos espacios un pasillo alargado que comunicaba con un balcón dispuesto hacia el jardín, con dos escaleras a ambos lados que permitirían el acceso al mismo [fig. 8].

Por lo que respecta a la planta alta de la Real Audiencia, las dependencias que nos encontraríamos serían: la sala de audiencia pública, la del crimen, la del acuerdo, la capilla de la audiencia, la sala de visitas, la de matos, la de ordenación, el gabinete, el tribunal de cuentas, la secretaría y la escribanía de cámara. Por su parte, la planta alta del cuartel la inmensa mayoría de espacio son de dormitorio para la tropa y oficiales.

\section{Plano cuarto}

Se presentan los perfiles correspondientes al palacio y a la Audiencia, Cárcel y Cuartel [fig. 9]. En el primero de manera longitudinal y en el segundo transversal lo que se ha buscado es mostrar los patios principales, con sus soportales y habitaciones anejas. En las leyendas explicativas se extraen datos interesantes de la construcción, como por ejemplo, las dimensiones de los muros.

En cuanto al palacio, el ancho corredor estaría cubierto por tejados planos en sus dos pisos, siendo el piso inferior de orden toscano y el superior de orden dórico. Las habitaciones superiores culminarían con tejados a dos aguas, cubriéndolo alguna suerte de armadura. Por lo que respecta a la segunda sección podemos resolver que la altura de estos edificios sería inferior a la del palacio, que todo el conjunto estaría cubierto a dos aguas, cuyos tejados, en voladizo y siguiendo su mismo grado de inclinación cubrirían el segundo piso de sus soportales, de menor anchura que los anteriores. Como último elemento reseñable podemos advertir que el patio de la cárcel presentaría arcadas de medio punto en el piso inferior.

\section{Planos quinto y sexto}

Los dos proyectos de fachada ejecutados por Donoso varían muy pocos meses en su ejecución, el primero está fechado el 5 de julio de 1781 [fig. 10] y presenta gran riqueza de detalles y de decoración; el segundo, datado el 11 de agosto [fig. 11] repite la misma estructura pero 


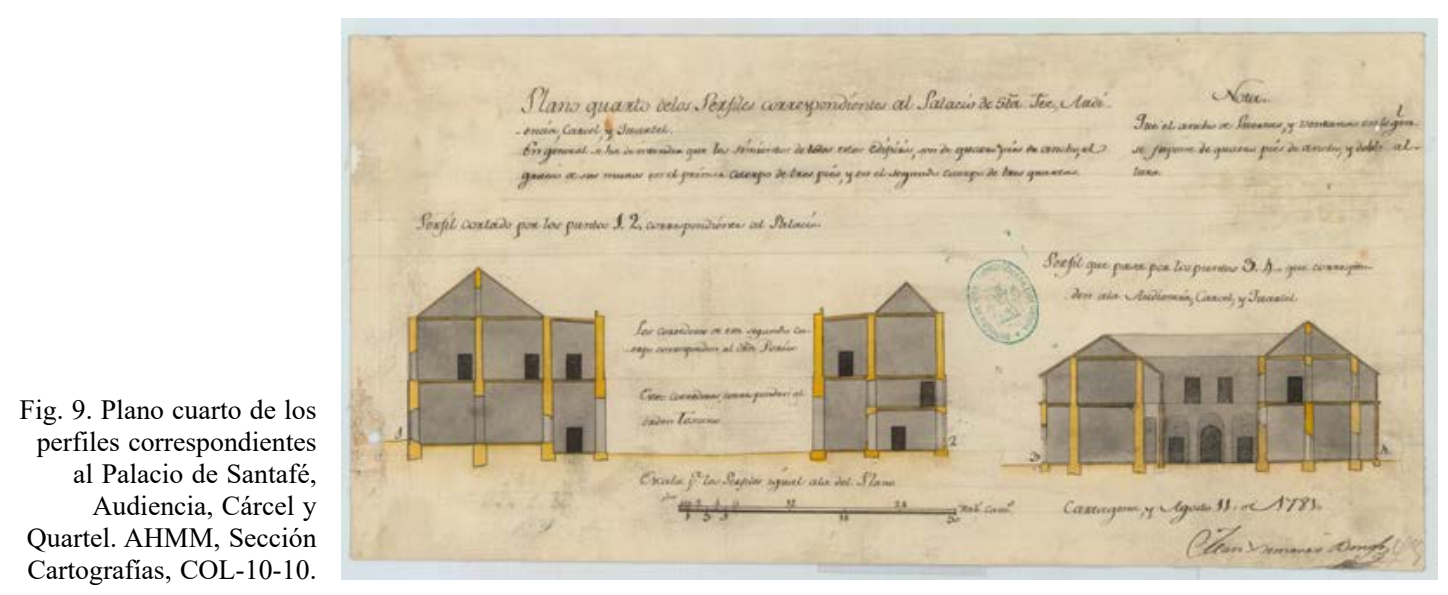

simplificando la ornamentación. A nuestro juicio esta reducción de elementos decorativos pudo deberse a la necesidad de abaratar el presupuesto que acompañaba a la primera propuesta.

En el primer plano se muestra la mitad de la fachada del palacio, organizado en dos pisos y con el cuerpo central diferenciado del resto de la estructura. El piso inferior presenta una arcada de medio punto separada por pilares a los que se adosan pilastras de orden toscano de gran anchura que se elevan hasta recibir el entablamento. En los extremos un doble juego de pilastras del mismo cariz cierra el conjunto. Las ventanas se abrirían de manera alterna hacia los arcos de la fachada haciendo juego con la puerta de entrada. En cuerpo superior encontramos grandes ventanales en sustitución de la arcada de acceso, con antepechos de balaustres y moldura exterior quebrada, dividiendo el espacio otra serie de pilastras de orden toscano ${ }^{47}$, más delgadas que las inferiores, recibirían también el entablamento de cierre. Éste se organizaría con triglifos y metopas, en las que se muestran diferentes elementos decorativos como leones, torres o castillos, guirnaldas, flechas, armaduras, etc. El conjunto remata con un antepecho superior dividido por pedestales a la misma altura que las pilastras inferiores, creando espacios longitudinales decorados con series de 9 tondos. Sobre los pedestales se han colocado una serie de armaduras con toda una serie de elementos añadidos formando estructuras decorativas muy interesantes, similares a trofeos. El cuerpo central, si bien se organiza de la misma manera, presenta un perfil saliente hacia el exterior, dotándolo de mayor corporeidad. En este caso las pilastras van a ser sustituidas por medias columnas del mismo orden. Se remata con un gran frontón, dispuesto sobre el entablamento, en cuyo tímpano se aprecia un escudo, presumiblemente el escudo de España, rodeado por una amplia guirnalda.

El segundo diseño repite exactamente el mismo esquema compositivo salvo en los elementos de cierre. El entablamento superior presenta la misma disposición en triglifos y metopas, pero sin elementos decorativos en estas últimas. El antepecho alto está dividido por los pedestales, pero sus muros son continuos, sin tondos ni otro detalle reseñable. Sobre los pedestales pequeños remates, a manera de pináculos, muy sencillos y terminados en esfera ${ }^{48}$.

Como colofón, podemos decir coincidiendo con Marco Dorta, que la severidad del conjunto de la fachada es de clara influencia palladiana, siendo un fiel exponente de la formación neoclásica de su autor ${ }^{49}$.

${ }^{47}$ En el plano se encuentra una doble leyenda: "Escala de 17.5 módulos correspondientes a 8 varas del primer piso o orden toscano" y "Escala de 20 módulos correspondientes a 6 2/3 varas del segundo cuerpo o orden dórico". En este sentido, al tener el patio principal esta distribución de órdenes, toscano en el inferior y dórico en el superior, nos asalta la duda si no repetiría el mismo esquema la fachada, sobre todo por localizarse estas leyendas en el pliego, no obstante, si atendemos al diseño en la fachada se percibe claramente que los dos órdenes de pilastras son del mismo orden y se correspondería con el toscano.

48 En la parte inferior de este plano se muestra una copia exacta de los perfiles descritos en el apartado anterior.

49 Marco, 1949: 93. 


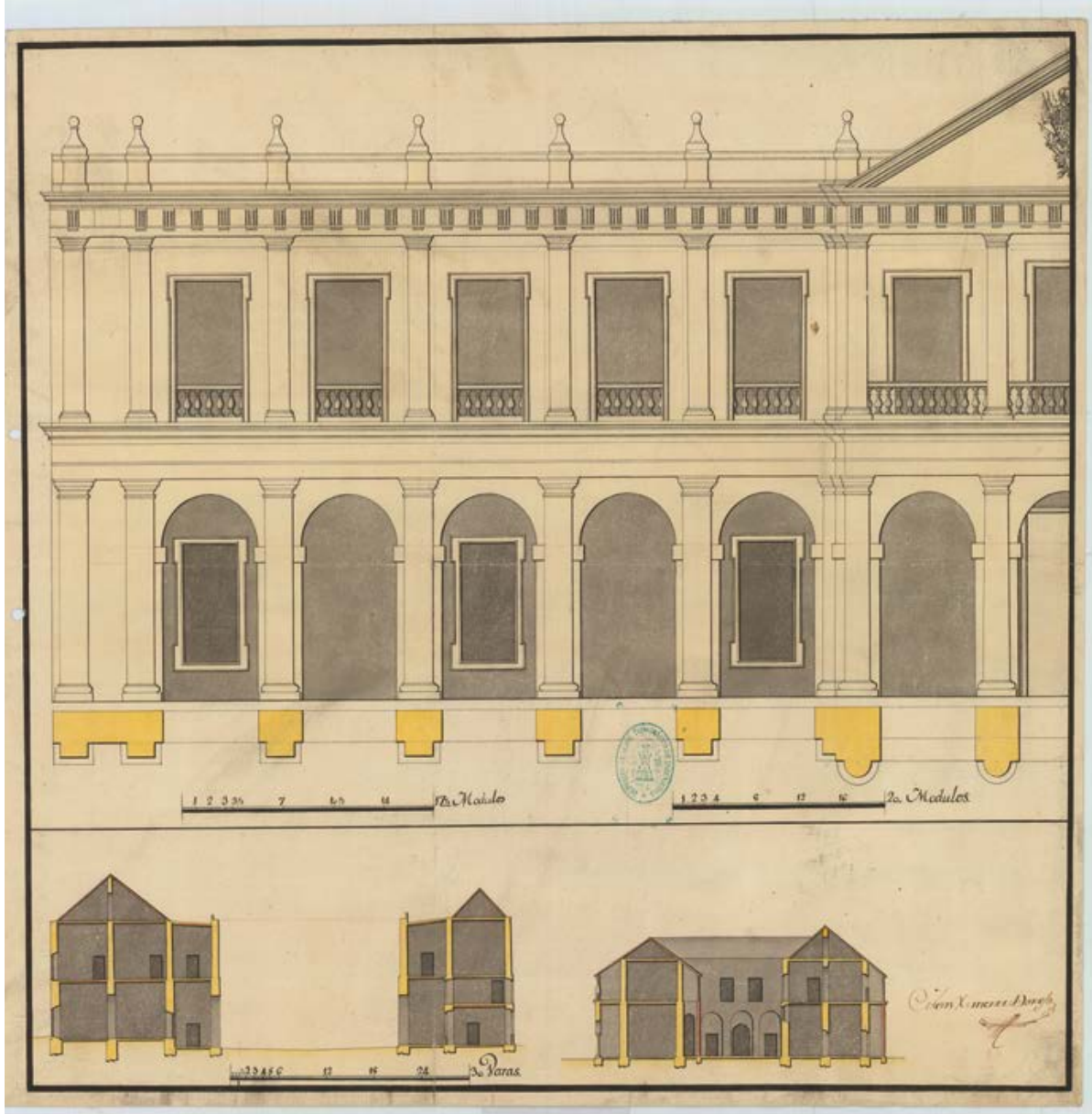

Fig. 10. Sin título, AHMM, Sección Cartografías, COL-10-03.

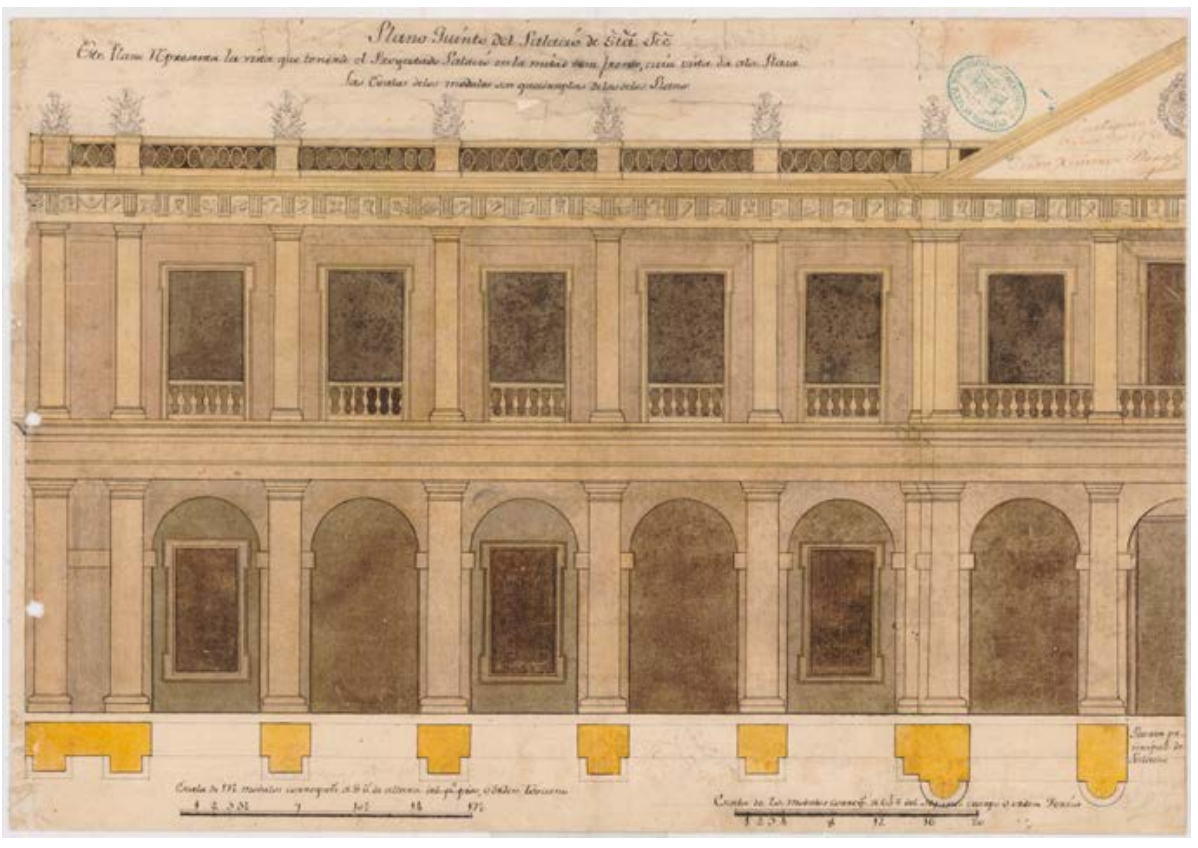

Fig. 11. Plano quinto del Palacio de Santafé, AHMM, Sección Cartografías, COL-10-11. 
Fig. 12. Plano de entresuelos del Palacio de Santafé, AHMM, Sección Cartografías, COL-10-02.

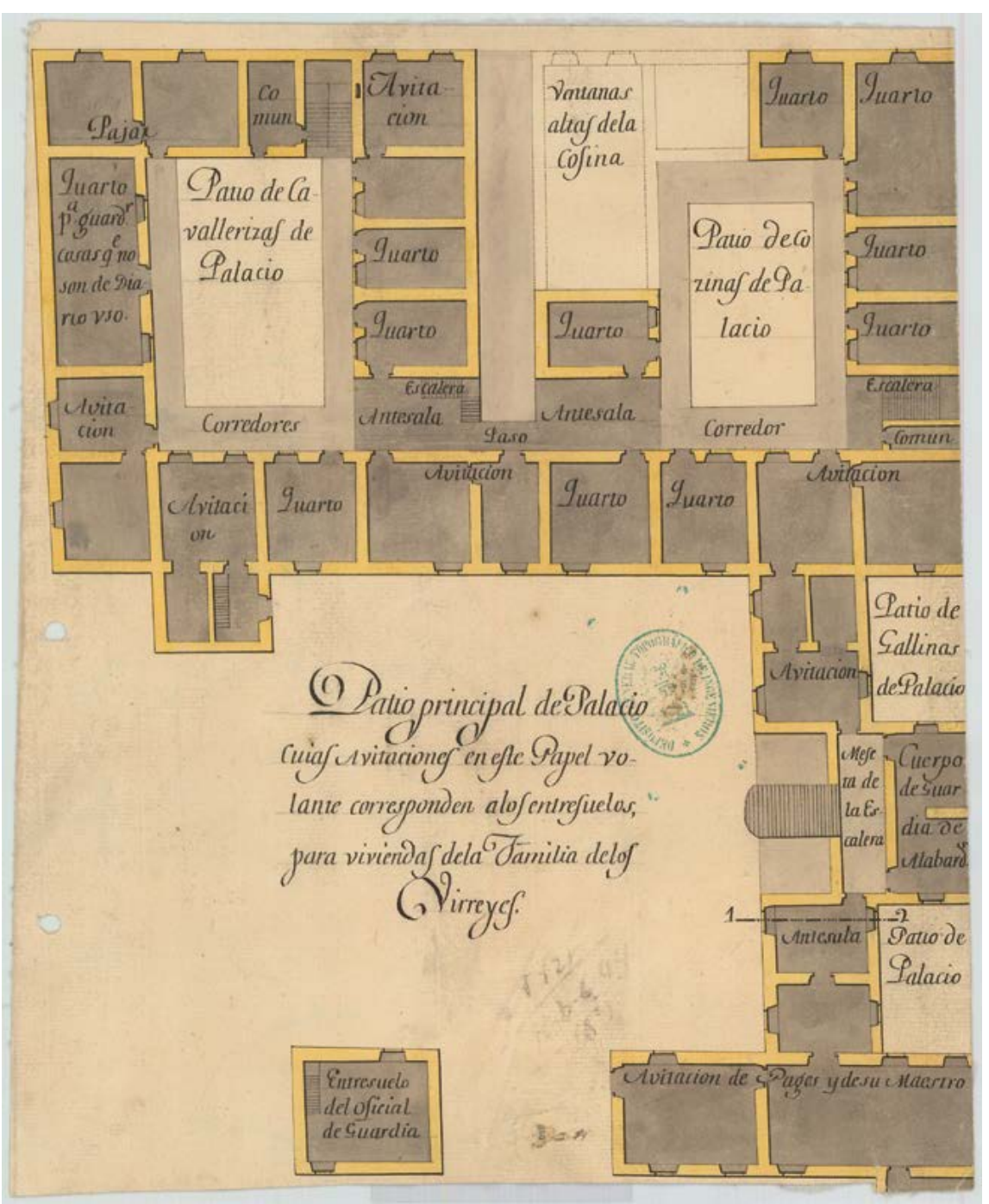

\section{Plano complementario}

Es un pliego o papel volante donde se muestra el patio principal del palacio con las habitaciones existentes en el entresuelo del edificio y que correspondería a las viviendas para la familia de los virreyes [fig. 12]. Se trata de un plano totalmente inédito que ayuda a comprender el sistema organizativo del palacio, así como la relación de los espacios.

A ambos lados de lo que sería la puerta de acceso al palacio se encuentran dos habitaciones, sin conexión entre ellas, que servían de complemento al cuarto del oficial de guardia, y habitaciones de pajes y de su maestro. Tras la meseta de la escalera principal se ubicaría el cuerpo de guardia de alabarderos, y el resto de la planta estaría destinado a cuartos para familiares del virrey.

\section{Conclusiones}

Como puede comprobarse a lo largo de este artículo algunos aspectos relativos a la historia constructiva del palacio de los virreyes de Bogotá son bastante desconocidos, sobre todo en lo 
tocante a los proyectos constructivos anteriores al incendio que terminó por destruirlo. Con todo, su trayectoria es la de un relato desafortunado de continuas reparaciones y catástrofes sobre un edificio antiquísimo, levantado de tapias de tierra, cuyos proyectos de reedificación nunca se llevaron a cabo, quedando sus ilustres residentes desprovistos de una dignidad "de habitación" que consideraban propia a su relevante cargo.

Gracias al plano primero realizado por el ingeniero Juan Jiménez Donoso conocemos cómo estaba estructurada la manzana, donde se levantaba no sólo el palacio real sino también la audiencia y la cárcel, y cómo se establecían las viejas comunicaciones entre ellos. Como advertimos este plano es crucial para la historia edilicia de este inmueble, pues nos muestra su organización interior con todo lujo de detalles, siendo una de las aportaciones documentales de nuestro estudio.

El proyecto de palacio elaborado por Jiménez Donoso es el más completo e interesante de los que se conservan; la distribución final de la manzana, las propuestas de fachadas y el entresuelo del palacio, inédito, son un conjunto de pliegos de enorme valor, como puede comprobarse. No obstante, aún quedan algunas incógnitas por resolver en relación a los costes del mismo y otros aspectos relativos a la obra general del ingeniero, del que aún no existe ningún estudio monográfico. Sobre estos aspectos seguiremos trabajando en el futuro esperando dilucidar alguno de ellos.

\section{BIBLIOGRAFÍA}

Capel Sáez, Horacio (1983): Los ingenieros militares en España, siglo XVIII: repertorio bibliográfico e inventario de su labor cientifica y espacial. Barcelona: Ediciones de la Universidad.

Castro Morales, Efraín (2003): Palacio Nacional de México: historia de su arquitectura. C. de México: Museo Mexicano.

Flórez de Ocáriz (1990): Genealogías del Nuevo Reino de Granada. Libro Primero. Bogotá: Instituto Caro y Cuervo e Instituto Colombiano de Cultura Hispánica.

Friede, Juan (1975-1976): Fuentes documentales para la historia del Nuevo Reino de Granada desde la instalación de la Real Audiencia de Santafé. Bogotá: Banco Popular.

Friede, Juan (1995): Documentos inéditos para la Historia de Colombia, coleccionados en el Archivo General de Indias de Sevilla. Bogotá: Academia de Historia de Colombia.

Gutiérrez, Ramón / Vallín, Rodolfo / Perfetti, Verónica (1999): Fray Domingo de Petrés y su obra arquitectónica en Colombia. Bogotá: Banco de la República / El Ancora Editores.

Jiménez Donoso, Juan (1794): Despertar o Avisos para la Instrucción de la juventud militar en el rompimiento de una guerra. Madrid: Imprenta Real. Tomo 1. Texto introductorio.

López Bejarano, Pilar (2006): "Control y desorden en Santafé de Bogotá (Nueva Granada). En torno a las reformas urbanas de finales del siglo XVIII". En: Brocar, 30, pp. 111-137.

Marco Dorta, Enrique (1949): “El Palacio de los Virreyes de Bogotá. Un proyecto fracasado". En: Anales del Instituto de Arte Americano e Investigaciones Estéticas, 2, pp. 88-98.

Martin Pastor, Eduardo (1938): De la vieja casa de Pizarro al nuevo Palacio de gobierno. Lima: Ministerio de Fomento y Obras Públicas.

Martínez, Carlos (1987): Santafé. Capital del Nuevo Reino de Granada. Bogotá: Ediciones PROA.

Mejía Pavony, Germán Rodrigo (2012): La ciudad de los conquistadores 1536-1604. Serie Historia de Bogotá. Bogotá: Editorial Pontificia Universidad Javeriana.

Mercurio histórico y político, Tomo 3, septiembre-diciembre de 1786. Madrid: Imprenta Real, p. 365.

Ojeda Pérez, Robert / Castellanos Alfonso, Adriana / Torres, Sebastián (2013): "Incendio en el Palacio Virreinal en Santafé: resonancia histórica y patrimonial”. En: Revista Módulo Arquitectura CUC, 12 (1), pp. 163-181.

Pérez, Felipe (1883): Geografía general física y politica de los Estados Unidos de Colombia y geografia particular de la ciudad de Bogotá. Bogotá: Imprenta de Echeverría Hnos.

Rodríguez Freyle, Juan (1979): El Carnero. Conquista y Descubrimiento del Nuevo Reino de Granada de las Indias Occidentales del Mar Océano y fundación de la ciudad de Santafé de Bogotá. Caracas: Biblioteca Ayacucho.

Fecha de recepción: 15-X-2019

Fecha de aceptación:05-V-2020

Archivo Español de Arte, vol. XCIII, n. ${ }^{\circ} 371$, pp. 259-276, julio-septiembre 2020 ISSN: 0004-0428, eISSN: 1988-8511, https://doi.org/10.3989/aearte.2020.17 